\title{
Wogonin Hampers Dexamethasone-Induced Oxidative Imbalance in Sprague Dawely Rats
}

\author{
Maha M. Hassanin $^{\text {a }}$, Mai F. Tolba ${ }^{\text {a,b }}$, Marianne G. Tadros ${ }^{\text {a }}$, Mohamed M. Elmazar ${ }^{\mathrm{c}}$, Abdel-Nasser Singab $^{* b, d}$ \\ ${ }^{a}$ Department of Pharmacology and Toxicology, Faculty of Pharmacy, Ain Shams University, Cairo 11566, Egypt \\ ${ }^{\mathrm{b}}$ Centre for Drug Discovery and Development Research, Ain Shams University, Cairo 11566, Egypt \\ ${ }^{\mathrm{c}}$ Department of Pharmacology and Toxicology, Faculty of Pharmacy, British University in Egypt, Egypt \\ ${ }^{\mathrm{d}}$ Department of Pharmacognosy, Faculty of Pharmacy, Ain Shams University, Cairo 11566, Egypt
}

\begin{abstract}
Corticosteroids are frequently used for their powerful anti-inflammatory activity in the management of various chronic inflammatory diseases. They are also used because of their potent immunosuppressive power in the manipulation of adverse effects associated with chemotherapeutic treatments. However, their long-term usage is associated with several side effects. The majority of these side effects are due to the increased oxidative stress associated with their administration. Dexamethasone (DEX) is one of the most commonly used glucocorticoids either as an anti-inflammatory and/or immunosuppressive agent. Wogonin, a mono-flavonoid present in the root of Scutellaria baicalensis Georgi, has attracted considerable attention in recent years. Wogonin has a well-documented antioxidant activity that is mainly responsible for its multiple pharmacological activities. The current study aimed at investigating the possible protective activity of wogonin against DEX-induced oxidative stress in Sprague Dawley rats. The results showed that wogonin co-treatment successfully counteracted DEX-induced oxidative stress. Co-administration of wogonin doses of 30 and $60 \mathrm{mg} / \mathrm{kg} / \mathrm{day}$ significantly improved superoxide dismutase (SOD) activity by $1.7(\mathrm{P}<0.001)$ and 3.9 folds $(\mathrm{P}<0.001)$ and significantly improved catalase (CAT) activity by 1.9 and 2.2 folds $(\mathrm{P}<0.05)$ as compared to DEX group. Moreover, co-treatment with wogonin $(30 \mathrm{mg} / \mathrm{kg} /$ day) improved reduced glutathione (GSH) level by 1.5 folds, while the higher dose significantly improved GSH level by 2.3 folds $(\mathrm{P}<0.05)$ as compared to DEX group. Also, co-treatment with wogonin improved serum malondialdehyde MDA level by $11.8 \%$ and $30 \%$ compared to the DEX group. In conclusion, wogonin displayed a promising protective antioxidant effect against DEX-induced oxidative stress.
\end{abstract}

Keywords: wogonin; flavonoids; oxidative stress; corticosteroids; rat.

*Correspondence | Abdel Nasser Singab; Department of Pharmacognosy, Faculty of Pharmacy, Ain Shams University, Cairo 11566, Egypt. Email: dean@pharma.asu.edu.eg

Citation | Hassanin MM, Tolba MF, Tadros MG, Elmazar MM, Singab A, 2020. Wogonin hampers against dexamethasone-induced oxidative imbalance in Sprague Dawley rats. Arch Pharm Sci ASU 4(1): 70-78

DOI: $10.21608 /$ APS.2020.2001.1028

Print ISSN: 2356-8380. Online ISSN: 2356-8399.

Received 22 November 2019. Accepted 04 December 2019.

Copyright: ${ }^{{ }^{2}} 2020$ Singab et al. This is an open-access article licensed under a Creative Commons Attribution 4.0 International License (CC BY 4.0), which permits unrestricted use, distribution, and reproduction in any medium, provided the original author(s) and source are credited. Published by: Ain Shams University, Faculty of Pharmacy

\section{INTRODUCTION}

Oxidative stress plays an important role in the pathogenesis of multiple diseases including obesity-associated metabolic syndrome [1], cancer $[\mathbf{2}, \mathbf{3}]$, neurodegenerative disease $[\mathbf{4}, \mathbf{5}]$, diabetes [6], renal diseases [7] and osteoporosis [8]. Oxidative stress results from an imbalance between the generation of reactive oxygen 
species and/or reactive nitrogen species [9]. Internal or natural defense mechanisms include either antioxidant (tocopherols, ascorbic acid, and glutathione) or antioxidant enzymes such as catalase (CAT), glutathione peroxidase (GPX) and superoxide dismutase (SOD) $[\mathbf{1 0}, \mathbf{1 1}]$. The consequences of oxidative stress are multiple including lipid peroxidation [12] and DNA damage [13]. This, in turn, causes the loss of cell viability either via necrotic or apoptotic pathways $[14,15]$.

Glucocorticoids are one of the most commonly used agents for the management of many chronic diseases [16]. They have a strong anti-inflammatory [17] and immunosuppressive activity [18]. These activities enhanced their choice for treating and managing inflammatory and immune-related disorders [19]. They are used as an adjuvant with chemotherapeutic agents [20] to manage their undesirable adverse effects such as pain and inflammation [21]. Unfortunately, they increase oxidative stress which in turn is associated with many side effects [22]. Dexamethasone (DEX), a glucocorticoid, has been reported to induce oxidative stress in many in vivo and in vitro studies [23, 24].

Modulation of oxidative stress is a key therapeutic target in various diseases $[4,25]$. Antioxidants are widely used in the management of various diseases as inflammatory conditions [26] and diabetes [27]. Wogonin (5,7-dihydroxy-8-methoxy flavone) is a naturally existing mono-flavonoid in Scutellaria Baicalensis Georgi root [28]. Wogonin showed numerous pharmacological activities such as antiinflammatory [29], antitumor [30], neuroprotective [31] and anti-diabetic activities [32]. Wogonin also has been reported to have a potential antioxidant activity [33, 34]. Accordingly, the current study aimed at investigating the potential protective activity of wogonin against DEX-induced oxidative stress in vivo in Sprague Dawley rats. The systemic oxidative imbalance was investigated by assessing several oxidative stress markers and antioxidant enzymes.

\section{METHODS}

\subsection{Experimental Animals}

A total of 40 male Sprague Dawley rats were obtained from the animal facility of Misr University for Science and Technology, 6th of October, Egypt. Animals were allowed a period of 2 weeks for adaptation with the environmental conditions of the animal facility at the Faculty of Pharmacy Ain Shams University. Throughout the study, the animals had free access to water and standard food pellets. The study protocol was approved by the ethical committee of the Faculty of Pharmacy Ain Shams University (ENRECASU.2019-95).

\subsection{Animal Treatment Protocol and Samples Collection}

The animals were randomly divided into four groups (10 rats per group), the first group was used as control while groups from 2-4 were treated with dexamethasone, intramuscularly (I.M.) once weekly for 5 weeks. Groups 3 and 4 were treated with wogonin (purity HPLC 99\%, SHAANXI XINHENG BIOTECH CO., LTD, China) intraperitoneally at doses $30 \mathrm{mg} / \mathrm{kg}$ and $60 \mathrm{mg} / \mathrm{kg} /$ day. Wogonin has dissolved in a mixture of saline and TWEEN 80 ratio 9:1 [35]. The doses were selected based on previously published data [36]. At the end of the week, 5 animals were euthanized and blood samples were collected from the retro-orbital sinus. Blood samples were allowed to clot then centrifuged at $15 \mathrm{~min}$ at $2500 \mathrm{rpm}$ at $4{ }^{\circ} \mathrm{C}$. Then the isolated serum samples were kept at $-20{ }^{\circ} \mathrm{C}$ freezer for subsequent evaluation of following oxidative stress markers. 


\subsection{Assessment of Serum Superoxide Dismutase (SOD) Activity}

SOD activity was assessed in serum specimens isolated from the different groups. The principle of SOD activity assay relies on the ability of this enzyme to inhibit the phenazine methosulphate-mediated reduction of nitrobluetetrazolium dye. Absorbance was measured at $560 \mathrm{~nm}$ and superoxide dismutase activity was expressed in the unit $(\mathrm{U}) / \mathrm{mL}$ [37].

\subsection{Determination of Catalase (CAT) Activity}

CAT activity (U/mL) was assessed in the isolated serum samples from the different groups using a catalase assay kit [38] purchased from Biodiagnostics (Giza, Egypt) following the manufacturer's recommendations. Absorbance was measured at $510 \mathrm{~nm}$ where there was an inverse relationship between catalase activity and released chromophore's color intensity.

\subsection{Determination of Reduced Glutathione (GSH) Serum Level}

Evaluation of the serum level of GSH $(\mathrm{mg} / \mathrm{dL})$ was based on the reduction of 2nitrobenzoic acid with GSH to produce a yellow compound. The yield chromogen is directly proportional to GSH concentration and its absorbance was measured at $405 \mathrm{~nm}$ [39].

\subsection{Assessment of Serum Lipid Peroxides Level}

Lipid peroxidation was estimated colorimetrically using the thiobarbituric acid reactive method [40]. Absorbance was measured at $534 \mathrm{~nm}$. Malondialdehyde (MDA) serum levels were expressed as $(\mathrm{nmol} / \mathrm{mL})$.

\subsection{Statistical Analysis}

Data are presented as the mean \pm SD. Comparisons were done via a one-way analysis of variance followed by Tukey- Kramer's post hoc test. Statistical significance was accepted at
$\mathrm{P}<0.05$. GraphPad Prism software, version 5.00 (GraphPad Software, La Jolla, CA) was used for statistical analysis and plotting the graphs.

\section{RESULTS}

\subsection{Effect of Wogonin on Serum SOD Activity}

Treatment of rats with the corticosteroid DEX significantly reduced SOD activity by $63.3 \%$ $(\mathrm{P}<0.001)$ vs control. However, co-administration of wogonin doses of 30 and $60 \mathrm{mg} / \mathrm{kg} / \mathrm{day}$ significantly improved SOD activity by 1.7 $(\mathrm{P}<0.001)$ and 3.9 folds $(\mathrm{P}<0.001)$ as compared to DEX group (Fig. 1).

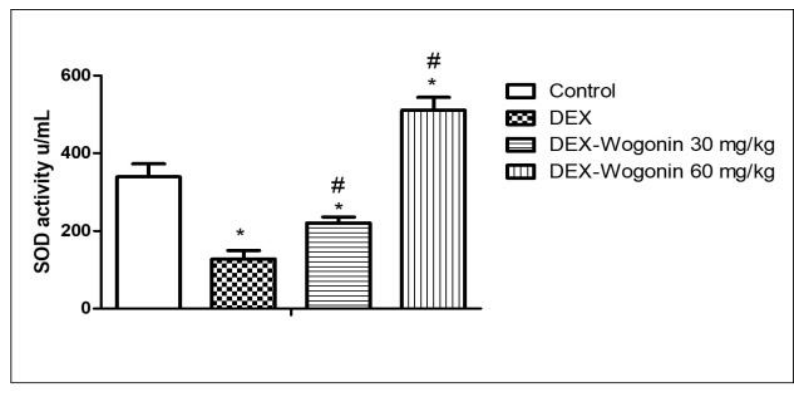

Fig. 1. Effect of wogonin co-treatment on dexamethasoneinduced alterations in SOD activity. Data are means \pm SD. $(n=10)$. ${ }^{*}$ indicates significant difference vs control at $\mathrm{p}<0.05 ;{ }^{\#}$ indicates significant difference vs DEX at $\mathrm{p}<0.05$.

\subsection{Effect of Wogonin on Serum CAT Activity}

Assessment of serum CAT activity showed that DEX treatment reduced CAT activity by $39.6 \%$ vs control. However, co-administration of wogonin doses of 30 and $60 \mathrm{mg} / \mathrm{kg} /$ day significantly improved CAT activity by 1.9 and 2.2 folds $(\mathrm{P}<0.05)$ as compared to DEX group (Fig. 2)

\subsection{Effect of Wogonin on Serum GSH Levels}

Treatment of rats with the corticosteroid DEX significantly reduced GSH level by $54.7 \%$ $(\mathrm{P}<0.05)$ vs control. Furthermore, co-treatment of wogonin doses of $30 \mathrm{mg} / \mathrm{kg} /$ day improved GSH level by 1.5 folds, while the higher dose 60 $\mathrm{mg} / \mathrm{kg} /$ day significantly improved GSH level by 2.3 folds $(\mathrm{P}<0.05)$ as compared to DEX group (Fig. 3). 


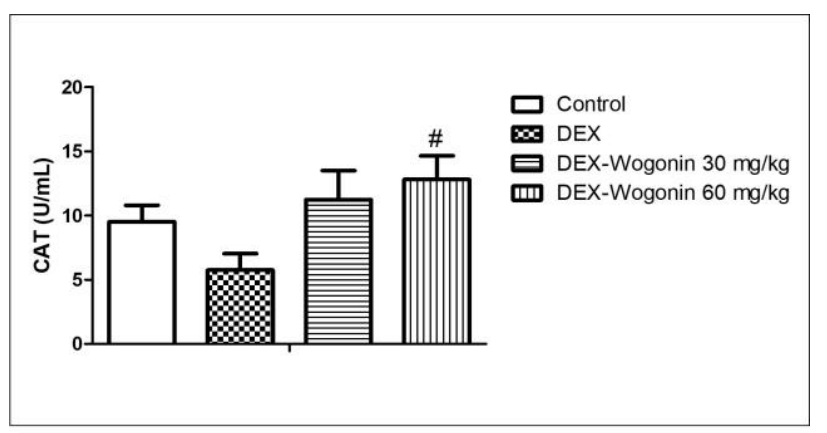

Fig. 2. Effect of wogonin co-treatment on dexamethasoneinduced alterations in catalase (CAT) activity. Data are means \pm SD. $(n=10)$. \# indicates significant difference vs DEX at $\mathrm{p}<0.05$.

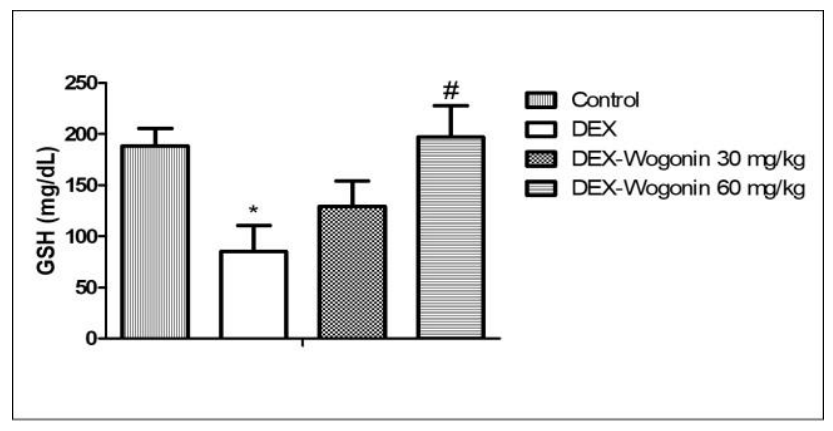

Fig. 3. Effect of wogonin co-treatment on dexamethasoneinduced alterations in GSH activity. Data are means \pm SD. $(\mathrm{n}=10) .{ }^{*}$ indicates significant difference vs control at $\mathrm{p}<0.05$; " indicates significant difference vs DEX at $\mathrm{p}<0.05$.

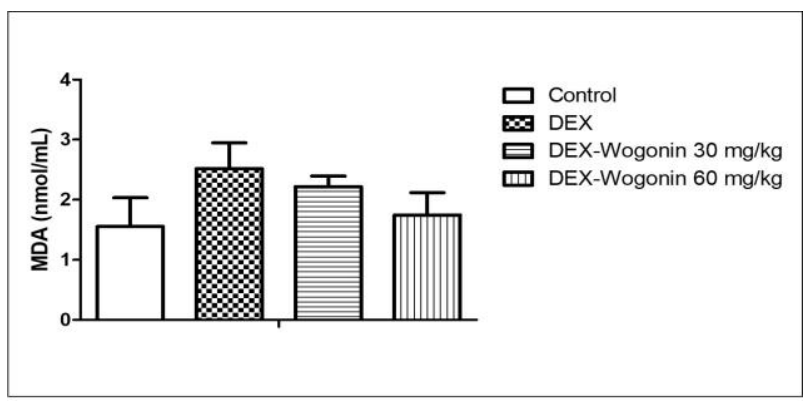

Fig. 4. Effect of wogonin co-treatment on dexamethasoneinduced alterations serum lipid peroxides (MDA). Data are means \pm SD. $(n=10)$.

\subsection{Effect of Wogonin on Serum Lipid Peroxides}

Evaluation of lipid peroxide levels in the serum indicated that rats treated with DEX showed an increased serum MDA level by 1.6 folds as compared to control. However, co- treatment of wogonin doses of 30 and 60 $\mathrm{mg} / \mathrm{kg} /$ day improved serum MDA level by $11.8 \%$ and 30\% compared to the DEX group (Fig. 4).

\section{DISCUSSION}

Dexamethasone (DEX) long-term usage is associated with adverse effects involving most major organ systems [22]. These adverse effects include osteoporosis [40], gastritis [42], hypertension [43], lipid disorders [44], neuropsychiatric [45], dermatological changes [46] and ocular hypertension [47]. The aforementioned adverse effects are mainly caused by increased oxidative stress $[\mathbf{2 2}, \mathbf{2 3}]$.

Imbalance in the oxidation status which is usually due to overproduction of reactive oxygen species (ROS) or defective in ROS defense capacities leads to subsequent damage at the cellular level which ultimately triggers secondary tissue injury in the affected target organs. The activities of the antioxidant enzymes including SOD, and CAT among the well-known markers that indicate the status of the endogenous defense systems against ROS. The level of reduced glutathione is an additional valid marker to predict the oxidative status [48]. Glutathione is capable of existing in different redox species. Therefore, it is implicated in the physiological functions that involve regulation of the thiolredox status. GSH is the reduced form of glutathione that is capable of neutralizing ROS and protecting normal cells against ROS mediated-damage [49]. The activity of SOD is essential to neutralize the superoxide radicals by transforming them into hydrogen peroxide. Catalase enzyme works on the generated hydrogen peroxide to produce water [50]. Lipid peroxidation and tissue injury [50] is the outcome of oxidative imbalance in case of reduced activity or levels of the inherent antioxidative defense systems. 
Herein, rat's challenge with dexamethasone resulted in abolished SOD and CAT activities as well as a marked depletion of GSH. Moreover, a slight increase in serum lipid peroxides was observed in dexamethasone-treated rats. Concurrent treatment of dexamethasone challenged rats with wogonin at either $30 \mathrm{mg} / \mathrm{kg}$ or $60 \mathrm{mg} / \mathrm{kg}$ doses improved the antioxidant defenses SOD, CAT, and GSH and alleviated dexamethasone-induced systemic oxidative imbalance. Our data are in line with previously published data which indicated that wogonin exhibits strong antioxidant activity in several in vitro and in vivo models [33, 34]. It was previously reported that wogonin protects against cadmium-triggered oxidative renal injury [52]. Studies also showed that the antioxidant activity of wogonin contributed to its protective effect against diabetes cardiomyopathy by enhancing CAT and SOD activities [53]. Moreover, previous work supported that wogonin enhanced both SOD and GSH serum levels and reduced the MDA level in a model of nonalcoholic fatty liver [54].

In conclusion, the current study showed that treatment with wogonin hampers the systemic oxidative imbalance induced by long term treatment with glucocorticoids like dexamethasone. Therefore, co-treatment with wogonin is anticipated to alleviate corticosteroid -mediated adverse reactions and complications. Studies are in progress in our laboratories to verify the effect of wogonin against dexamethasone target specific adverse effects.

\section{Declarations}

\section{Ethics Approval and Consent to Participate}

The animal treatment protocol was approved by the research ethics committee of the Faculty of Pharmacy, Ain Shams University.

\section{Consent to Publish}

All the authors approved the final manuscript and agreed on the publishing of the submitted work in the APS journal.

\section{Availability of Data and Materials}

All data generated or analyzed during this study are included in this published article in the main manuscript.

\section{Competing Interests}

The authors declare that there is no conflict of interest.

\section{Funding Statement}

No funding was received.

\section{Acknowledgment}

The authors would like to acknowledge all colleagues in the Faculty of Pharmacy, Ain Shams University for their support.

\section{REFERENCES}

1. Furukawa S, Fujita T, Shimabukuro M, Iwaki M, Yamada Y, Nakajima Y, et al., Increased oxidative stress in obesity and its impact on metabolic syndrome. J Clin Invest 2004. 114(12): 1752-61. https://doi.org/10.1172/JCI21625

2. Thanan R, Oikawa S, Hiraku Y, Ohnishi S, Ma N, Pinlaor S, et al., Oxidative stress and its significant roles in neurodegenerative diseases and cancer. Int J Mol Sci 2015. 16(1): 193-217. https://doi.org/10.3390/ijms16010193

3. Saha SK, Lee SB, Won J, Choi HY, Kim K, Yang G-M, et al., Correlation between oxidative stress, nutrition, and cancer initiation. Int J Mol Sci 2017. 18(7): 1544. https://doi.org/10.3390/ijms18071544

4. Poprad P, Jomova K, Simunkova M, Kollar V, Rhodes CJ, and Valko MJTips, Targeting free radicals in oxidative stress-related human diseases. J Trends Pharmacol Sci 2017. 38(7): 592-607. 
https://doi.org/10.1016/j.tips.2017.04.005

5. Lalkovičová $M$ and Danielisová VJNrr, Neuroprotection and antioxidants. J Neural Regen Res 2016. 11(6): 865-874.

6. Asmat U, Abad K, and Ismail KJSPJ, Diabetes mellitus and oxidative stress-A concise review. J Saudi Pharm. 2016. 24(5): 547-553.

https://doi.org/10.1016/j.jsps.2015.03.013

7. Noiri E, Nakao A, Uchida K, Tsukahara H, Ohno M, Fujita $\mathrm{T}$, et al., Oxidative and nitrosative stress in acute renal ischemia. Am J Physiol Renal Physiol 2001. https://doi.org/10.1152/ajprenal.0071.2001

8. Domazetovic V, Marcucci $\mathrm{G}$, Iantomasi $\mathrm{T}$, Brandi ML, Vincenzini MTJCCiM, and Metabolism B, Oxidative stress in bone remodeling: role of antioxidants. Clin Cases Miner Bone Metab. 2017. 14(2): 209-216 https://doi.org/10.11138/ccmbm/2017.14.1.20 9

9. Sies H, Berndt C, and Jones DPJArob, Oxidative stress. J Annu Rev Biochem 2017. 86: 715-748. https://doi.org/10.1146/annurevbiochem-061516-045037

10. Nimse SB and Pal DJRA, Free radicals, natural antioxidants, and their reaction mechanisms. J Res Adv 2015. 5(35): 2798628006.

https://doi.org/10.1039/C4RA13315C

11.Ighodaro $\mathrm{O}$ and Akinloye OJAJoM, First line defense antioxidants-superoxide dismutase (SOD), catalase (CAT) and glutathione peroxidase (GPX): Their fundamental role in the entire antioxidant defense grid. J Alexandria Journal of Medicine 2018. 54(4): 287-293.

https://doi.org/10.1016/j.ajme.2017.09.001

12. Gaschler MM, Stockwell BRJB. Lipid peroxidation in cell death. J Biochem Biophys
Res Com 2017. 482(3): 419-425. https://doi.org/10.1016/j.bbrc.2016.10.086

13. Li Y, Wei L, Cao J, Qiu L, Jiang X, Li P, et al., Oxidative stress, DNA damage and antioxidant enzyme activities in the pacific white shrimp (Litopenaeus vannamei) when exposed to hypoxia and reoxygenation. J Chemosphere 2016. 144: 234-240. https://doi.org/10.1016/j.chemosphere.2015.0 8.051

14. Skipper A, Sims J, Yedjou C, Tchounwou PJIjoer. Cadmium chloride induces DNA damage and apoptosis of human liver carcinoma cells via oxidative stress. Int $\mathbf{J}$ Environ Res Public Health 2016. 13(1): 88. https://doi.org/10.3390/ijerph13010088

15. Li B, Li W, Tian Y, Guo S, Qian L, Xu D, et al., Selenium-Alleviated Hepatocyte Necrosis and DNA Damage in CyclophosphamideTreated Geese by Mitigating Oxidative Stress. Biol Trace Elem Res. 2019: 1-9. https://doi.org/10.1007/s12011-019-01717-3

16. Desmet SJ and De Bosscher KJTJoci, Glucocorticoid receptors: finding the middle ground. J Clin Invest 2017. 127(4): 11361145. https://doi.org/10.1172/JCI88886

17. Oh K-S, Patel H, Gottschalk RA, Lee WS, Baek S, Fraser ID, et al., Anti-inflammatory chromatinscape suggests alternative mechanisms of glucocorticoid receptor action. J Immunity 2017. 47(2): 298-309. e5. https://doi.org/10.1016/j.immuni.2017.07.012

18. Cain DW and Cidlowski JAJNRI, Immune regulation by glucocorticoids. J Nat Rev Immunol 2017. 17(4): 233-247. https://doi.org/10.1038/nri.2017.1

19. Williams DMJRc, Clinical Pharmacology of Corticosteroids. J Respir Care 2018. 63(6): 655-670.

https://doi.org/10.4187/respcare.06314 
20. Haywood A, Good P, Khan S, Leupp A, Jenkins-Marsh S, Rickett K, et al., Corticosteroids for the management of cancer-related pain in adults. J Cochrane Database Syst Rev 2015 (4). https://doi.org/10.1002/14651858.CD010756. pub2

21. De Santis $M$ and Saad FJU, Practical guidance on the role of corticosteroids in the treatment of metastatic castration-resistant prostate cancer. J Urology 2016. 96: 156-164. https://doi.org/10.1016/j.urology.2016.02.010

22. Oray M, Abu Samra K, Ebrahimiadib N, Meese H, and Foster CSJEoods, Long-term side effects of glucocorticoids. J Expert Opin Drug Saf 2016. 15(4): 457-465. https://doi.org/10.1517/14740338.2016.11407 43

23. Suwanjang W, Abramov AY, Charngkaew K, Govitrapong P, and Chetsawang BJNi, Melatonin prevents cytosolic calcium overload, mitochondrial damage and cell death due to toxically high doses of dexamethasone-induced oxidative stress in human neuroblastoma SH-SY5Y cells. J Neurochem Int 2016. 97: 34-41. https://doi.org/10.1016/j.neuint.2016.05.003

24. Polycarp TN, Yusoff SM, Benjamin EO, Salisi SM, and Bejo S-KJCCP, Influence of dexamethasone-induced stress on oxidative stress biomarkers in non-pregnant does experimentally infected with Brucella melitensis. J Comp Clin Pathol 2017. 26(2): 423-435. https://doi.org/10.1007/s00580-0162395-x

25. Dennis JM and Witting PKJN, Protective role for antioxidants in acute kidney disease. J $\begin{array}{lll}\text { Nutr } & 2017 . & 9(7):\end{array}$ https://doi.org/10.3390/nu9070718

26. Athreya K and Xavier MFJN, Antioxidants in the treatment of cancer. J Nutr Cancer 2017. 69(8): p. 1099-1104. https://doi.org/10.1080/01635581.2017.13624 45

27. Golbidi $S$ and Laher I, Targeting Complications of Diabetes with Antioxidants. Nutritional Antioxidant Therapies: Treatments and Perspectives. 2017. 397-445. https://doi.org/ 10.1007/978-3-319-676258_16

28. Tan H, Li X, Yang W-H, and Kang YJJoBOojot BUoO, A flavone, Wogonin from Scutellaria baicalensis inhibits the proliferation of human colorectal cancer cells by inducing of autophagy, apoptosis, and G2/M cell cycle arrest via modulating the PI3K/AKT and STAT3 signaling pathways. J Journal of BUON 2019. 24(3): 1143-1149.

29. Khan NM, Haseeb A, Ansari MY, Devarapalli P, Haynie S, Haqqi TMJFRB, et al., Wogonin, a plant-derived small molecule, exerts potent anti-inflammatory and chondroprotective effects through the activation of ROS/ERK/Nrf2 signaling pathways in human Osteoarthritis chondrocytes. J Free Radic Biol Med 2017. 106:

288-301. https://doi.org/10.1016/j.freeradbiomed.2017. 02.041

30. Rubin J, Bo J, Denying W, Chihong Z, Jianguo F, and Linhui GJBri, Therapy effects of wogonin on ovarian cancer cells. J BioMed Res Int 2017. https://doi.org/10.1155/2017/9381513

31. Chen F, Wu R, Zhu Z, Yin W, Xiong M, Sun $\mathrm{J}$, et al., Wogonin protects rat dorsal root ganglion neurons against tunicamycininduced ER stress through the PERK-eIF2 $\alpha$ ATF4 signaling pathway. J Mol Neurosci $2015.55(4)$ : 995-1005 https://doi.org/10.1007/s12031-014-0456-7 
32. Khan S and Kamal MAJCpd, Wogonin Alleviates Hyperglycemia Through Increased Glucose Entry into Cells Via AKT/GLUT4 Pathway. J Curr Pharm Des 2019. 25(23): 2602-2606.

https://doi.org/10.2174/138161282566619072 2115410

33. Bei W, Jing L, Chen NJC, and Biointerfaces SB, Cardio Protective Role of Wogonin loaded Nanoparticle against Isoproterenol Induced Myocardial Infarction by Moderating Oxidative Stress and Inflammation. J Colloids Surf B: Biointerfaces 2019. 185: 110635. https://doi.org/10.1016/j.colsurfb.2019.11063 5

34. Huang Y, Guo L, Chitti R, Sreeharsha N, Mishra A, Gubbiyappa SK, et al., Wogonin ameliorates complete Freund's adjuvantinduced rheumatoid arthritis via targeting NF- $\kappa \mathrm{B} / \mathrm{MAPK}$ signaling pathway. J BioFactors 2019. https://doi.org/10.1002/biof.1585

35. Tseng TL, Chen MF, Liu CH, Pang CY, Hsu $\mathrm{YH}$, and Lee TJJBjop, Induction of endothelium-dependent constriction of mesenteric arteries in endotoxemic hypotensive shock. Br J Pharmacol 2016. 173(7):

$1179-1195$

https://doi.org/10.1111/bph.13415

36. Zhao Y, Yao J, Wu XP, Zhao L, Zhou YX, Zhang Y, et al., Wogonin suppresses human alveolar adenocarcinoma cell A549 migration in inflammatory microenvironment by modulating the IL-6/STAT3 signaling pathway. J Mol Carcinog 2015. 54(S1): E81E93. https://doi.org/10.1002/mc.22182

37. Sun, Y., Oberley, L.W. and Li, Y. A simple method for clinical assay of superoxide dismutase. Clin. Chem 1988. 34(3): 497-500

38. Aebi H, [13] Catalase in vitro. Methods
Enzymol $1984 . \quad 105: \quad 121-126$. https://doi.org/0.1016/S0076-6879(84)050163

39. Anderson ME, [70] Determination of glutathione and glutathione disulfide in biological samples. Methods Enzymol 1985. 113: 548-555. https://doi.org/10.1016/S00766879(85)13073-9

40. Ohkawa H, Ohishi N, and Yagi KJAb, Assay for lipid peroxides in animal tissues by the thiobarbituric acid reaction. J Anal Biochem $1979.95(2):$ 351-358. https://doi.org/10.1016/0003-2697(79)907383

41. Hu H, Li Z, Lu M, Yun X, Li W, Liu C, et al., Osteoactivin inhibits dexamethasoneinduced osteoporosis through up-regulating integrin $\beta 1$ and activate the ERK pathway. $\mathrm{J}$ Biomed Pharmacother 2018. 105: 66-72. https://doi.org/10.1016/j.biopha.2018.05.051

42. Zaha by E, Ali A, Alim AA, and El Sharawy AFJEJoHM, Role of Rebamipide andlor Pantoprazole in Preventing Dexamethasone Induced Gastritis in Senile Male Albino Rats. Egyptian J Hosp Med 2017. 67(2): 789-805. https://doi.org/10.12816/0037837

43. di Villa Bianca RdE, Mitidieri E, Donnarumma E, Tramontano T, Brancaleone V, Cirino G, et al., Hydrogen sulfide is involved in dexamethasone-induced hypertension in the rat. J Nitric Oxide 2015. 46: 80-86. https://doi.org/10.1016/j.niox.2014.11.013

44. Barbosa AM, Francisco PdC, Motta K, Chagas TR, dos Santos C, Rafacho A, et al., Fish oil supplementation attenuates changes in plasma lipids caused by dexamethasone treatment in rats. J Appl Physiol Nutr Metab $2016 . \quad$ 41(4): 382-390. https://doi.org/10.1139/apnm-2015-0487 
45. Yates NJ, Robertson D, Rodger J, and Martin-Iverson MTJPo, Effects of neonatal dexamethasone exposure on adult neuropsychiatric traits in rats. $\mathrm{J}$ PloS one $2016 . \quad 11(12)$ : e0167220. https://doi.org/10.1371/journal.pone.0167220

46. Lee KE, Youm JK, Lee WJ, Kang S, and Kim YJJEd, Polyphenol-rich apple extract inhibits dexamethasone-induced sebaceous lipids production by regulating SREBP 1 expression. J Exp Dermatol 2017. 26(10): 958-960. https://doi.org/10.1111/exd.13319

47. Patel GC, Phan TN, Maddineni P, Kasetti RB, Millar JC, Clark AF, et al., Dexamethasone-induced ocular hypertension in mice: Effects of myocilin and route of administration. Am J Pathol 2017. 187(4): 713-723.

https://doi.org/10.1016/j.ajpath.2016.12.003

48. Brzović-Šarić V, Landeka I, Šarić B, Barberić M, Andrijašević L, Cerovski B, et al., Levels of selected oxidative stress markers in the vitreous and serum of diabetic retinopathy patients. J Mol Vis 2015. 21: 64964.

49. Forman HJ, Zhang $H$, and Rinna A., Glutathione: an overview of its protective roles, measurement, and biosynthesis. Mol. Aspects Med. 2009. 30(1-2): 1-12. https://doi.org/10.1016/j.mam.2008.08.006

50. Ibrahim W. H., Habib H. M., Kamal H., Clair D. K. S., and Chow C. K., Mitochondrial superoxide mediates labile iron level: evidence from Mn-SOD-transgenic mice and heterozygous knockout mice and isolated rat liver mitochondria. Free Radic Biol Med 2013. 65: 143-149. https://doi.org/10.1016/j.freeradbiomed.2013. 06.026

51. Biberoglu EH, Kirby A, Dirican AÖ, Genc
M, Avci A, Doganay B, et al., Alterations in lipid peroxidation and T-cell function in women with hyperemesis gravidarum. J Obstet Gynaecol. 2016. 36(1): 93-96. https://doi.org/10.3109/01443615.2015.10306 04

52. Jiao D, Jiang Q, Liu Y, and Ji L, Nephroprotective effect of wogonin against cadmium-induced nephrotoxicity via inhibition of oxidative stress-induced MAPK and NF-kB pathway in Sprague Dawley rats. J Hum Exp Toxicol 2019. 38(9): 1082-1091 https://doi.org/10.1177/0960327119842635

53. Khan S, Zhang D, Zhang Y, Li M, and Wang C, Wogonin attenuates diabetic cardiomyopathy through its anti-inflammatory and anti-oxidative properties. J Mol Cell Endocrinol 2016. 428: $101-8$ https://doi.org/10.1016/j.mce.2016.03.025

54. Chen J, Liu J, Wang Y, Hu X, Zhou F, Hu Y, et al., Wogonin mitigates nonalcoholic fatty liver disease via enhancing PPARalpha/AdipoR2, in vivo and in vitro. $\mathrm{J}$ Biomed Pharmacother 2017. 91: 621-631 https://doi.org/10.1016/j.biopha.2017.04.125 